\title{
Severe Gout
}

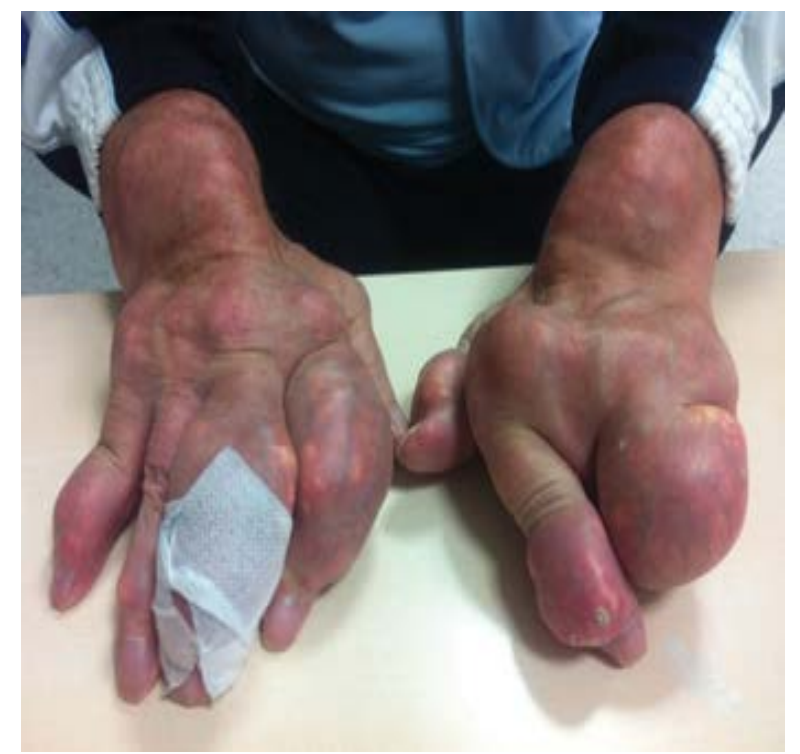

Figure 1: A 59-year-old man presented to the Rheumatology clinic showing important deformities in both hands.

Keywords: Rheumatology; Severe gout; Hypertension; Nephrophaty; Dyslipemia

\section{Case History}

Previously diagnosed gout, never started urate lowering therapies and did not have the correct lifestyle and dietetic measures, developing chronic gout without any medical control. Tophi develop due to deposition of monosodium urate in articular, periarticular and subcutaneos tissues. He presented important tophi in both hands generating severe functional limitation Instead of re-starting urate lowering treatment, the patient didn't follow our recommendations and developed not only local complications (such as infection tophi that underwent complete amputation of the $3^{\text {rd }}$ finger of the left hand) but systemic cardiovascular complications related to chronic deposit of urate like uric acid nephrophaty, hypertension, dyslipemia showing the narrow link between hyperuricemia and increased risk of metabolic syndrome and other cardiovascular disorders. It is our duty as physicians to warn the patient of the importance of follow the recommendations as well as insisting on the vital importance of the follow up and the adherence to treatment (Figure 1).

*Corresponding author: Riazuelo JRL, Department of Rheumatology, Hospital del Henares, Coslada, Madrid, Spain, Tel (34) 91911912000 ; E-mail: txerralamua@hotmail.com

Citation: Riazuelo JRL (2019) Severe Gout. Int J Clin Med Imaging 6: 632. doi:10.4172/2376-0249.1000632

Copyright: (C) 2019 Riazuelo JRL. This is an open-access article distributed under the terms of the Creative Commons Attribution License, which permits unrestricted use, distribution, and reproduction in any medium, provided the original author and source are credited. 